\title{
Upaya Meningkatkan Kemampuan Guru dalam Menerapkan Pembelajaran Tematik melalui In hOuse Training di SDK Diller
}

\author{
Tresia Aleksa \\ Kepala Sekolah SDK Diller, Sikka, Nusa Tenggara Timur \\ Email: tresiaaleksa1772@gmail.com \\ Doi : 10.32672/jsa.v7i5.1517
}

\begin{abstract}
ABSTRAK
Tujuan penelitian ini adalah meningkatkan pemahaman guru terhadap konsep pembelajaran tematik dan meningkatkan kreativitas guru dalam melakukan pembelajaran. Metode yang di gunakan pada penelitian ini adalah penelitian tindakan sekolah (PTS) dengan langkah-langkah persiapan, pelaksanaan, evaluasi dan refleksi. Pada siklus 1 diperoleh persentase guru yang mengajar dengan metode/ model pembelajaran baru sebesar $69 \%$ meningkat menjadi $100 \%$ pada siklus kedua atau semua guru telah menggunakan pembelajaran yang non persial. Penerpan In House Training dapat meningkatkan pemahaman guru terhadap konsep pembelajaran tematik, professional guru pada saat pembelajaran tematik di SDK Diller, kreativitas guru dalam menentukan langkah-langkah dalam kegiatan pembelajaran tematik di kelas dan pembelajaran menjadi lebih efektif dan meningkatkan prestasi belajar siswa.
\end{abstract}

Kata kunci: Kemampuan Guru, In House Training, Tematik.

\section{PENDAHULUAN}

Upaya memperbaiki dan meningkatkan mutu pendidikan seakan tidak pernah berhenti. Banyak agenda reformasi yang telah, sedang, dan akan dilaksanakan. Reformasi pendidikan adalah restrukturisasi pendidikan, yakni memperbaiki pola hubungan sekolah dengan lingkungannya dan dengan pemerintah, pola pengembangan perencanaan, serta pola pengembangan manajerialnya, pemberdayaan guru dan restrukturisasi model model pembelajaran.

Reformasi pendidikan tidak cukup hanya dengan perubahan dalam sektor kurikulum, baik struktur maupun prosedur penulisannya. Pembaharuan kurikulum akan lebih bermakna bila diikuti oleh perubahan praktik pembelajaran di dalam maupun di luar kelas. Keberhasilan implementasi kurikulum sangat dipengaruhi oleh kemampuan guru yang akan menerapkan dan mengaktualisasikan kurikulum tersebut. Tidak jarang kegagalan implementasi kurikulum disebabkan oleh kurangnya pengetahuan, keterampilan dan kemampuan guru dalam memahami tugas tugas yang harus dilaksanakannya. Hal itu berarti bahwa guru sebagai pelaksana kegiatan pembelajaran menjadi kunci atas keterlaksanaan kurikulum di sekolah.

Berdasarkan supervisi yang dilakukan, guru kelas belum pernah mengikuti pelatihan bagaimana melakukan pembelajaran tematik kurikulum 2013, sehingga dalam menyajikan pembelajaran guru masih pada pembelajaran persial dan hasil belajar siswa 
rata-rata masih tergolong rendah. Kurikulum 2013 menuntut siswa yang lebih aktif dalam proses pembelajaran, guru sebagai fasilitator pada saat proses pembelajaran berlangsung. Dengan permasalahan di atas maka perlu dilakukan pelatihan In House Training terhadap guru. Penerapan In House Training merupakan salah satu model training yang isi materi dan durasi training disesuaikan dengan permintaan dari sekolah. Adapun tujuan dilakukan pelatihan In House Training ini supaya guru lebih professional dalam melakukan pembelajaran sehingga tujuan pembelajaran bias tercapai dengan baik dan efesien.

Menurut Dharmawan (2016) Pada in-house training tahap 1 terdapat 50\% guru berhasil menyelesaikan tugas-tugas PTK dan pada tahap 2 terdapat $60 \%$ guru berhasil menyusun laporan PTK. Jadi ada peningkatan kemampuan guru dalam menyusun PTK yang cukup signifikan. Kondisi tersebut tentu tidak bisa dibiarkan terus menerus, tetapi harus ada solusi dan tindakan nyata dari kepala sekolah sebagai penanggungjawab keberhasilan pendidikan di sekolahnya. Para guru tersebut harus mendapatkan pembinaan atau pelatihan agar mampu meningkatkan pemahaman terhadap konsep pemahaman pembelajaran tematik, meningkatkan kreativitas dalam menentukan langkah-langkah pembelajaran tematik di kelas agar pembelajaran lebih efektif, dan meningkatkan prestasi belajar siswa.

Selain dapat meningkatkan kemampuan guru dalam pembelajaran tematik, guru juga diharapkan dapat meningkatkan kemampuannya dalam menyusun rencana pembelajaran, terutama bagi guru-guru yang memang tidak memiliki latar belakang pendidikan keguruan. Upaya perwujudan pengembangan silabus menjadi perencanaan pembelajaran yang implementatif memerlukan kemampuan yang komprehensif. Kemampuan itulah yang dapat mengantarkan guru menjadi tenaga yang professional. Guru yang professional harus memiliki 5 (lima) kompetensi yang salah satunya adalah kompetensi penyusunan rencana pembelajaran. Namun dalam kenyataannya masih banyak guru yang belum mampu menyusun rencana pembelajaran sehingga hal ini secara otomatis berimbas pada kualitas out put yang dihasilkan dalam proses pembelajaran.

\section{METODE PENELITIAN}

\section{Pentahapan Penelitian Tindakan}

Penelitian ini dilakukan dalam tiga tahapan, yaitu persiapan, pelaksanaan dan evaluasi dan refleksi, dan dilakukan minimal dalam dua siklus. Pada tahap persiapan dibuat dibuat skenario kegiatan, jadwal waktu, tempat serta sarana pendukung lainnya seperti lembar observasi dan angket.

\section{Tindakan}

Langkah-langkah PTS yaitu: perencanaan, pelaksanaan, pengamatan, dan refleksi. Langkah-langkah PTS disajikan pada gambar berikut: 
Tresia Aleksa

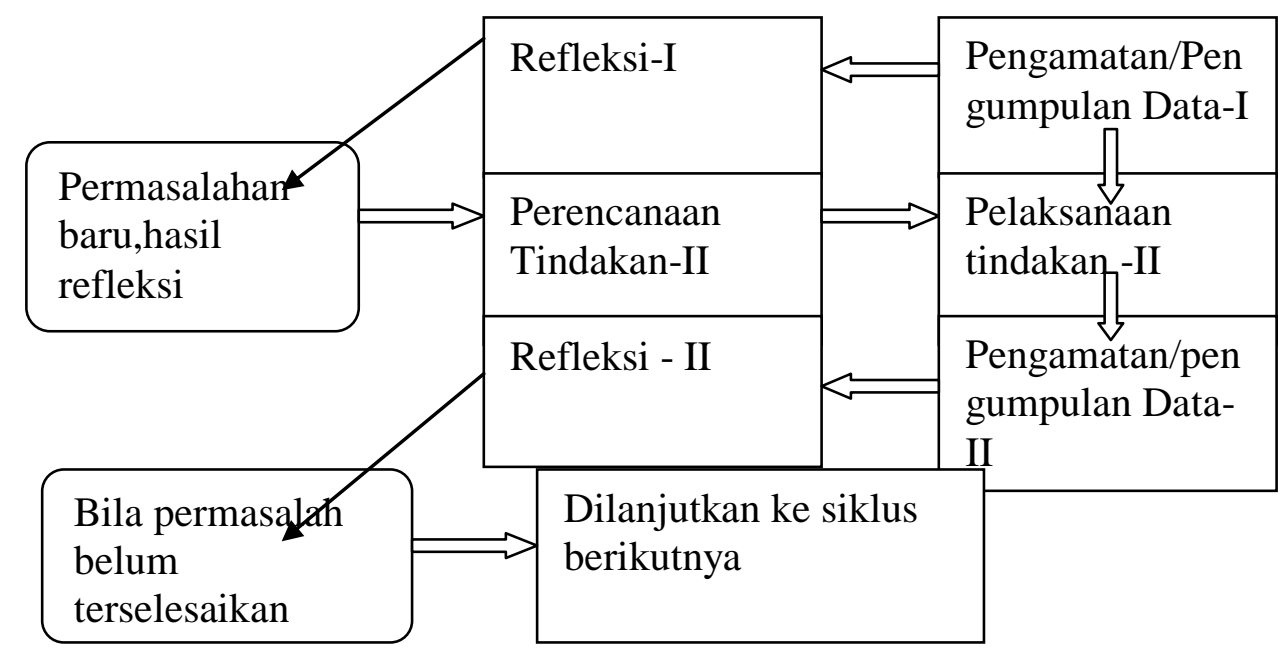

Gambar 1. Langkah-langkah PTS (Direktorat Tendik, 2008)

\section{Siklus I}

Langkah pelaksanaan PTS adalah sebagai berikut (1) Perencanaan permasalahan rendahnya kualitas pemebelajaran yang dilakukan, kemudian melakukan supervisi dan evaluasi bersama guru. (2) Tindakan, menerapkan supervisi kelas (supervisi saat pembelajaran). (3) Pengamatan. melakukan supervisi kelas dengan format supervisi dan melakukan pengamatan hasil supervisi dengan menggunakan format hasil supervisi. (4) Refleksi, melakukan evaluasi tindakan yang dilkukan dengan meliputi evaluasi mutu, jumlah dan waktu dari setiap macam tindakan. Melakukan pertemuan untuk membahas hasil evaluasi tentang skenario, memperbaiki pelaksanaan tindakan sesuai hasil evaluasi untuk digunakan pada siklus berikutnya.

\section{Siklus II}

Perencanaan siklus II berdasarkan hasil análisis refleksi siklus I, penyempurnaan rencana tindakan siklus II. Tindakan, menerapkan supervisi (supervisi pembelajaran)

Untuk menentukan keberhasilan tindakan dalam PTS ini perlu dibuat indiatorindikator keberhasilan PTS. Adapun indikator keberhasilan tindakan dalam PTS (penelitian tindakan sekolah) disajikan pada tabel berikut:

Tabel 1. Indikator keberhasilan PTS (Penelitian Tindakan Sekolah)

\begin{tabular}{llc}
\hline NO $\quad$ Indikator Keberhasilan & Rincian Sub Indikator: \\
& PTS & Guru yang kualitas pembelajarannya meningkat \\
& $(80 \%)$ \\
\hline 1 & Semakin meningkatnya & Datang ke kelas tepat waktu \\
& $\square$ Membuat persiapan mengajar \\
& $\square$ Menggunakan waktu secara efektif, efisien \\
& untuk mengajar \\
& $\square$ Guru selalu hadir di kelas \\
&
\end{tabular}


Serambi Akademica

Jurnal Pendidikan, Sains, dan Humaniora

2

Semakin berkualitasnya
pembelajaran yang
Dilakukan
Vol. 7, No. 5,

Oktober 2019

$\neg$ Perangkat pembelajaran

guru lengkap

Guru menggunakan media/ alat peraga

Guru Menggunakan metode/ model

pembelajaran yang up to date
pISSN 2337-8085

eISSN 2657- 0998

yang dipersiapkan

\section{HASIL DAN PEMBAHASAN}

Setelah tindakan II (siklus II) dilaksanakan, kemudian diobservasi, maka hasil yang didapatkan adalah sebagai berikut:

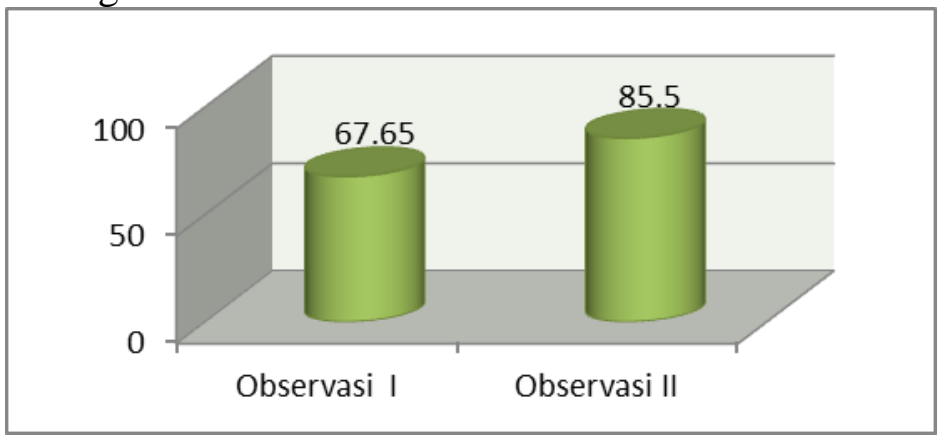

Gambar 1. Hasil Observasi I dan II.

Gambar 1. hasil observasi pada siklus I menunjukkan $67.65 \%$, data ini menunjukkan bahwa masih di bawah rata-rata. Kemudian dilanjutkan observasi pada siklus II sehingga mendapatkan hasil $85.5 \%$ ini menunjukkan penerapan In House Training berhasil diterapkan di kelas tematik. Setelah dilakukan observasi kemudian dilanjutkan dengan pretes siklus I dan II, yang disajikan pada gambar berikut.

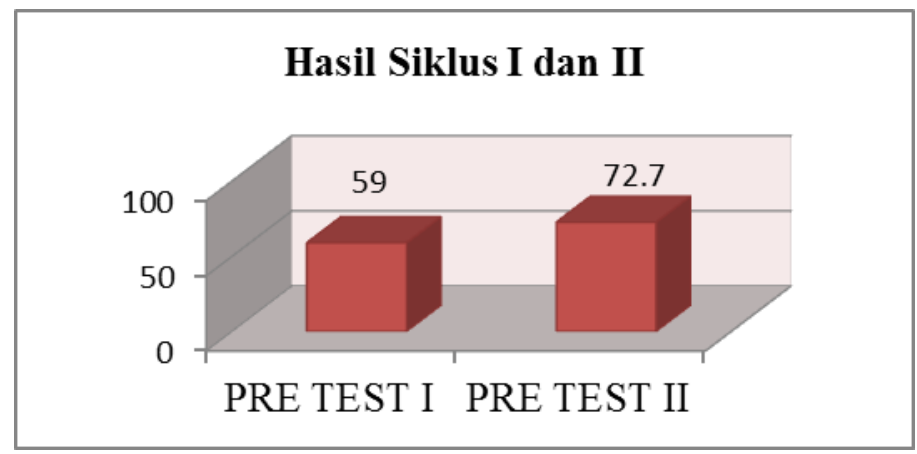

Gambar 2. Hasil Analisis Presentase siklus I dan II

Gambar 2. Menunjukkan hasil pretest sikulus I sebesar 59\% dan II sebesar 72.2, pada tahap ini menunjukkan bahwa ada peningkatan hasil yang di capai oleh siswa. Selanjutnya guru melakukan posttest yang ditunjukkan pada gambar berikut. 
Tresia Aleksa

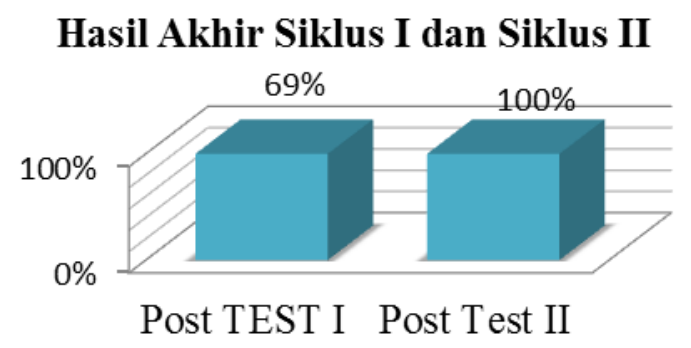

Grafik 3. Hasil akhir siklus I dan II

Supervisi kelas merupakan supervisi akademik yang membantu guru untuk mengembangkan kemampuannya. Pada penelitian ini terlihat jelas peningkatan kualitas pembelajaran yang terlihat dari indikator-indikator sebagai berikut:

Pembinaan terhadap kedisiplinan guru senantiasa dilaksanakan sepanjang waktu namun demikian komitmen para guru masih rendah. Hal ini perlu kesabaran dari seorang supervisor terlebih SDK Diller di Kecamatan Koting, Kab. Sikka, Nusa Tenggara Timur. Supervisi yang secara rutin dan terprogram dapat meningkatkan disiplin para guru untuk lebih komitmen terhadap tugas dan tanggung jawabnya sebagai pendidik.

Pada siklus 1 diperoleh persentase guru yang melengkapi perangkat pembelajaran sebesar $67,65 \%$ meningkat menjadi $85,5 \%$ pada siklus 2 . Dengan demikian pelaksanaan supervisi pembelajaran yang dilakukan dengan pendekatan bimbingan dan jeda waktu dapat meningkatkan jumlah guru yang menyiapkan secara lengkap perangkat pembelajarannya. Penerapan in-house training tahap 1 terdapat $50 \%$ guru berhasil menyelesaikan tugas-tugas PTK dan pada tahap 2 terdapat $60 \%$ guru berhasil menyusun laporan PTK (Dharmawan, 2016).

\section{Penerapan In House Training pada guru di SDK Diller}

Pada siklus 1 diperoleh persentase guru yang mengajar dengan metode/ model pembelajaran baru sebesar $69 \%$ meningkat menjadi $100 \%$ pada siklus kedua atau semua guru telah menggunakan pembelajaran yang non persial. Penerapan in-house training tahap 1 terdapat 50\% guru berhasil menyelesaikan tugas-tugas PTK dan pada tahap 2 terdapat 60\% guru berhasil menyusun laporan PTK (Dharmawan, 2016). Pelaksanaan supervisi kelas yang dilaksanakan terbukti dapat meningkatkan kualitas pembelajaran hal ini terjadi karena guru yang sedang disupervisi tidak merasa canggung/ takut dalam melaksanakan pembelajaran. Dalam kegiatan supervisi ini supervisor lebih bertindak membimbing dan membantu guru yang disupervisi.

\section{KESIMPULAN}

Adapun kesimpulan yang bias didapatkan pada penerapan In House Training ini sebagai berikut:

1. Penerpan In House Training dapat meningkatkan pemahaman guru terhadap konsep pembelajaran tematik 
2. Penerapan In House Training dapat meningkatkan professional guru pada saat pembelajaran tematik di SDK Diller.

3. Penerapan In House Training dapat meningkatkan kreativitas guru dalam menentukan langkah-langkah dalam kegiatan pembelajaran tematik di kelas dan pembelajaran menjadi lebih efektif

4. Penerapan In House Training dapat meningkatkan prestasi belajar siswa.

\section{DAFTAR PUSTAKA}

Hamalik, O. 2001. Proses Belajar Mengajar. Jakarta: Bumi Aksara.

Iskandar. 2009. Psikologi Pendidikan. Jakarta: Gaong Pustaka.

Mansur, S dan Loli. M.P.P. 2019. Upaya Meningkatkan Hasil Belajar Siswa Kelas VII dengan Model Guide Note Taking di SMP San Karlos Habi. Uin Raden Intan Lampung. BIOSFER: Jurnal Tadris Biologi. 10 (1): 21-28. DOI: https://doi.org/10.24042/biosfer.v10i1.3990

Dirmin dan Juarsih, C. 2014. Teori Belajar dan Prinsip-Prinsip Pembelajaran yang Mendidik. Jakarta : Rineka Cipta.

Dharmawan. K, Ramona. Y, Rupiasih. N. N, 2016. Model Pembinaan 'In-House Training' sebagai upaya untuk Meningkatkan kemampuan guru dalam penelitian dan Penulisan karya ilmiah. Jurnal Udayana Mengabdi. UKSW

Gulo, W. 2002. Strategi Belajar Mengajar. Jakarta: Grasindo

Hamalik, O. 2015. Kurikulum dan Pembelajaran. Jakarta: PT Bumi Aksara

Hamdani. 2011. Strategi Belajar Mengajar. Bandung : Pustaka Setia.

Hardini, I. dan Puspita, D. (2012) Strategi Pembelajaran Terpadu. Yogyakarta:

Familia

Kusmawati, R. Omegawati, W, H. 2010. PR Biologi Untuk SMA/MA Kelas X/2Kalten: Intan Pariwara.

Lutfi. 2007. Strategi Pembelajaran Biologi Teori, Praktik dan Penelitian. UNP Press: Padang 